\title{
Development of Bisphosphonate-Conjugated Antibiotics to Overcome Pharmacodynamic Limitations of Local Therapy: Initial Results with Carbamate Linked Sitafloxacin and Tedizolid
}

\author{
Emmanuela Adjei-Sowah 1,2,†, Yue Peng 1,3,†, Jason Weeks ${ }^{1}$, Jennifer H. Jonason ${ }^{1,4}$, Karen L. de Mesy Bentley ${ }^{1,3,4}$, \\ Elysia Masters ${ }^{1,2}$, Yugo Morita 1,4 ${ }^{\mathbb{D}}$, Gowrishankar Muthukrishnan 1,4 ${ }^{\mathbb{D}}$, Philip Cherian ${ }^{5}$, X. Eric Hu ${ }^{5}$, \\ Charles E. McKenna ${ }^{6}$, Frank H. Ebetino ${ }^{5,7}$ (D), Shuting Sun ${ }^{5, *}$, Edward M. Schwarz ${ }^{1,2,3,4}$ iD and Chao Xie ${ }^{1,4, *}$
}

1 Center for Musculoskeletal Research, University of Rochester Medical Center, Rochester, NY 14642, USA; eadjeiso@UR.Rochester.edu (E.A.-S.); Yue_Peng@URMC.Rochester.edu (Y.P.); jweeks3@u.rochester.edu (J.W.); Jennifer_Jonason@urmc.rochster.edu (J.H.J.); Karen_Bentley@urmc.rochester.edu (K.L.d.M.B.); emaster5@ur.rochester.edu (E.M.); Yugo_Morita@urmc.rochster.edu (Y.M.);

Gowri_Shankar@urmc.rochester.edu (G.M.); Edward_Schwarz@urmc.rochster.edu (E.M.S.)

check for

updates

Citation: Adjei-Sowah, E.; Peng, Y.; Weeks, J.; Jonason, J.H.; de Mesy Bentley, K.L.; Masters, E.; Morita, Y.; Muthukrishnan, G.; Cherian, P.; Hu, X.E.; et al. Development of

Bisphosphonate-Conjugated Antibiotics to Overcome Pharmacodynamic Limitations of Local Therapy: Initial Results with Carbamate Linked Sitafloxacin and Tedizolid. Antibiotics 2021, 10, 732. https: / / doi.org/10.3390/ antibiotics 10060732

Academic Editors: Débora C. Cora-ça-Huber, Eliana Aparecida de Rezende Duek and Marina Angélica Marciano da Silva

Received: 16 May 2021

Accepted: 14 June 2021

Published: 17 June 2021

Publisher's Note: MDPI stays neutral with regard to jurisdictional claims in published maps and institutional affiliations.

Copyright: (c) 2021 by the authors. Licensee MDPI, Basel, Switzerland. This article is an open access article distributed under the terms and conditions of the Creative Commons Attribution (CC BY) license (https:/ / creativecommons.org/licenses/by/ $4.0 /)$.
2 Department of Biomedical Engineering, University of Rochester, Rochester, NY 14642, USA

3 Department of Pathology, University of Rochester Medical Center, Rochester, NY 14642, USA

4 Department of Orthopaedics, University of Rochester Medical Center, Rochester, NY 14642, USA

5 BioVinc, LLC, Pasadena, CA 91107, USA; ptcherian@biovinc.com (P.C.); eric.hu@biovinc.com (X.E.H.); halebetino@biovinc.com (F.H.E.)

6 Department of Chemistry, University of Southern California, Los Angeles, CA 90089, USA; mckenna@usc.edu

7 Department of Chemistry, University of Rochester, Rochester, NY 14642, USA

* Correspondence: Shuting.Sun@biovinc.com (S.S.); Chao_Xie@urmc.rochster.edu (C.X.); Tel.: +1-310-730-5609 (S.S.); +1-585-2750818 (C.X.); Fax: +1-585-2762177 (C.X.)

$+\quad$ These authors contributed equally to this work.

\begin{abstract}
The use of local antibiotics to treat bone infections has been questioned due to a lack of clinical efficacy and emerging information about Staphylococcus aureus colonization of the osteocytelacuno canalicular network (OLCN). Here we propose bisphosphonate-conjugated antibiotics (BCA) using a "target and release" approach to deliver antibiotics to bone infection sites. A fluorescent bisphosphonate probe was used to demonstrate bone surface labeling adjacent to bacteria in a S. aureus infected mouse tibiae model. Bisphosphonate and hydroxybisphosphonate conjugates of sitafloxacin and tedizolid (BCA) were synthesized using hydroxyphenyl and aminophenyl carbamate linkers, respectively. The conjugates were adequately stable in serum. Their cytolytic activity versus parent drug on MSSA and MRSA static biofilms grown on hydroxyapatite discs was established by scanning electron microscopy. Sitafloxacin $O$-phenyl carbamate BCA was effective in eradicating static biofilm: no colony formation units (CFU) were recovered following treatment with $800 \mathrm{mg} / \mathrm{L}$ of either the bisphosphonate or $\alpha$-hydroxybisphosphonate conjugated drug $(p<0.001)$. In contrast, the less labile tedizolid $N$-phenyl carbamate linked BCA had limited efficacy against MSSA, and MRSA. CFU were recovered from all tedizolid BCA treatments. These results demonstrate the feasibility of BCA eradication of $S$. aureus biofilm on OLCN bone surfaces and support in vivo drug development of a sitafloxacin BCA.
\end{abstract}

Keywords: osteomyelitis; Staphylococcus aureus; antibiotic; bisphosphonate; scanning electron microscopy

\section{Introduction}

Bone infection, primarily caused by Staphylococcus aureus, remains a scourge in orthopaedic surgery. Although the incidence of infection following primary total joint replacement (TJR) is low $(\sim 1 \%)$ [1-3], reinfection rates are very high $(15-40 \%)$ after treatment of an infection related to a joint replacement [4-8], which has led to the established paradigm that $S$. aureus infection of bone is incurable [9]. The original standard of care 
treatment algorithm for implant-associated osteomyelitis was established in the 1970s and involves: (1) removal of the infected implant, (2) extensive surgical debridement of adjacent bone and soft tissues, and (3) filling of the bone void with antibiotic-loaded bone cement (ALBC) [10]. Initial studies on the effectiveness of this algorithm in the 1980s revealed that S. aureus was the most commonly encountered organism, and that the five-year success (survival) rate was only 77\% [11]. Remarkably, the results from the 2018 International Consensus Meeting (ICM) on Musculoskeletal Infections (MSKI) reported no changes in prosthetic joint infection (PJI) rates, the primary pathogen, treatment algorithm, and poor outcomes since this original standard of care was established half a century ago [1-3]. Thus, it is clear that both conceptual innovations to improve our understanding of the problem, and technical innovations to enhance diagnosis and treatment, are needed to improve clinical outcomes from $S$. aureus osteomyelitis.

Currently, the management of PJI is not universally standardized, but generally includes both systemic antibiotics and surgical debridement with exchange arthroplasty in one or two stages. There is great variation in management of the infection using poly(methyl methacrylate) (PMMA) ALBC and short ( $\sim$ weeks) and long (>3 months) courses of parenteral and oral antibiotic therapy, respectively [12]. The choice of antibiotic is usually based on etiologic diagnosis (culture and sensitivity of the infecting organism). ALBC is usually used in two-stage exchange arthroplasty in the form of spacers, beads, rods, and other custom spacers. Commonly used antibiotics include gentamicin, tobramycin, and vancomycin powder depending on the microbial organism [13]. While common, this practice has limitations, including microscopic imperfections in hand mixed and molded spacers that could lead to mechanical failure and/or poor release kinetics [14], which necessitates high loading of antibiotics that could theoretically lead to antibiotic resistance and acute renal failure [13]. Additionally, ALBCs are temporary spacers, and must be removed after the management of infection to allow for bone reconstruction. A recent comprehensive review of ALBC use for prophylaxis in primary TJR indicated that this approach is not supported by scientific evidence or health care savings considerations [15]. Thus, a systemic therapy that specifically targets the bone surface most susceptible to infection following orthopaedic implant surgery (prophylaxis), and the interface between biofilm bacteria and chronically infected bone (treatment), would appear to be an ideal goal for novel antibiotic therapies.

The recent discovery of $S$. aureus colonization of the osteocyte lacuno canalicular network (OLCN) of live bone via transmission electron microscopy (TEM) analyses of infected bone from mice, and bone biopsies from patients with chronic osteomyelitis, has provided new insights into the problems of antibiotic therapy to treat bone infections [16-19]. Specifically, S. aureus within the OLCN is a permanent reservoir of bacteria that cannot be eradicated by host responses or any known treatments short of amputation [9,20-22]. While in vivo bromodeoxyuridine labeling studies in mice have demonstrated that orally administered small molecules have access to $S$. aureus at the leading edge of the colony within the OLCN [17], we have also shown that both methicillin-sensitive S. aureus (MSSA) [23] and methicillin-resistant S. aureus (MRSA) [24] OLCN invasion cannot be prevented or eradicated by combined high-dose local and systemic antibiotics, likely due to its well-known adaptive responses that are associated with persister cells and small colony variants (SCVs) [10]. Thus, OLCN invasion might limit the availability of conventional antibiotics to levels below the minimum inhibitory concentration (MIC) and minimum biofilm eradication concentration (MBEC), and therefore activates biological mechanisms of antibiotic tolerance, such as the doubling of the bacterial cell wall thickness that we observed [23]. Therefore, a bone targeted antibiotic whose local concentration can increase over the MIC and MBEC is highly desirable to treat these deep bone infections.

Due to the overall challenges associated with osteomyelitis treatment, we and others have introduced bone-targeting conjugates to achieve higher or more sustained local therapeutic concentrations of antibiotic in bone while minimizing systemic exposure [25]. 
Specifically, we proposed conjugation of fluoroquinolone antibiotics to osteoadsorptive bisphosphonates (BPs) as a promising approach due to the long clinical track record of safety of the individual drug constituents, and their advantageous biochemical properties $[26,27]$. As an initial proof of concept, we evaluated BP-conjugated ciprofloxacin, utilizing a "target and release" chemical strategy in vitro, and in a rat model of implant-associated osteomyelitis [28]. In vitro studies demonstrated strong drug binding to hydroxyapatite, and an effective bactericidal profile with sustained release of the parent antibiotic over time. The in vivo results showed that a single dose of $10 \mathrm{mg} / \mathrm{kg}(15.6 \mathrm{mumol} / \mathrm{kg})$ conjugate reduced the colony forming units (CFU) in tissues by $99 \%$ and was one order of magnitude more potent than the parent antibiotic ciprofloxacin $(30 \mathrm{mg} / \mathrm{kg}, 90.6 \mathrm{mumol} / \mathrm{kg})$ given in multiple doses.

Another poorly recognized limitation of conventional antibiotic administration is the effect of local wound drainage on the pharmacodynamics of the therapy. In addressing the question of why local antibiotic therapies are ineffective, a recent international consensus meeting on ALBC highlighted the fact that there is interstitial fluid flow that drains from the bone infection to the surrounding soft tissues [10], as illustrated in Figure 1. This creates convection in the opposite direction, which could thwart all local antibiotic therapies. Here again, BP-conjugated antibiotics are expected to have an advantage via their accumulation at the bone-bacteria interface. To test this, we conducted a pilot study in which mice with established $S$. aureus osteomyelitis were treated with a BP-conjugated fluorescent probe (AF647-ZOL) [29] and undemineralized histology was performed to assess labeling at the infection site. Due to the limited efficacy of the first generation fluoroquinolone-conjugated BPs on established biofilms [30-32], we selected the newer generation fluoroquinolone, such as sitafloxacin, and an oxazolidinone antibiotic, tedizolid, and investigated novel BP and $\alpha$-hydroxybisphosphonate (HBP) conjugates of those antibiotics, which were synthesized with hydroxyphenylethane carbamate and amino phenylethane carbamate linkers respectively that we believe offer sufficient serum stability to permit delivery of the drugs to the bone surface. Here we present the results of these studies, which provide the first evidence that BP-conjugated drugs given to infected mice concentrate on the cortical surface between the bone and bacteria. We also present evidence of the potent cytolytic activity of sitafloxacin conjugated BP and HBP on MSSA and MRSA static biofilms grown on hydroxyapatite discs in vitro, versus parent antibiotic and tedizolid conjugated BP and HBP. 


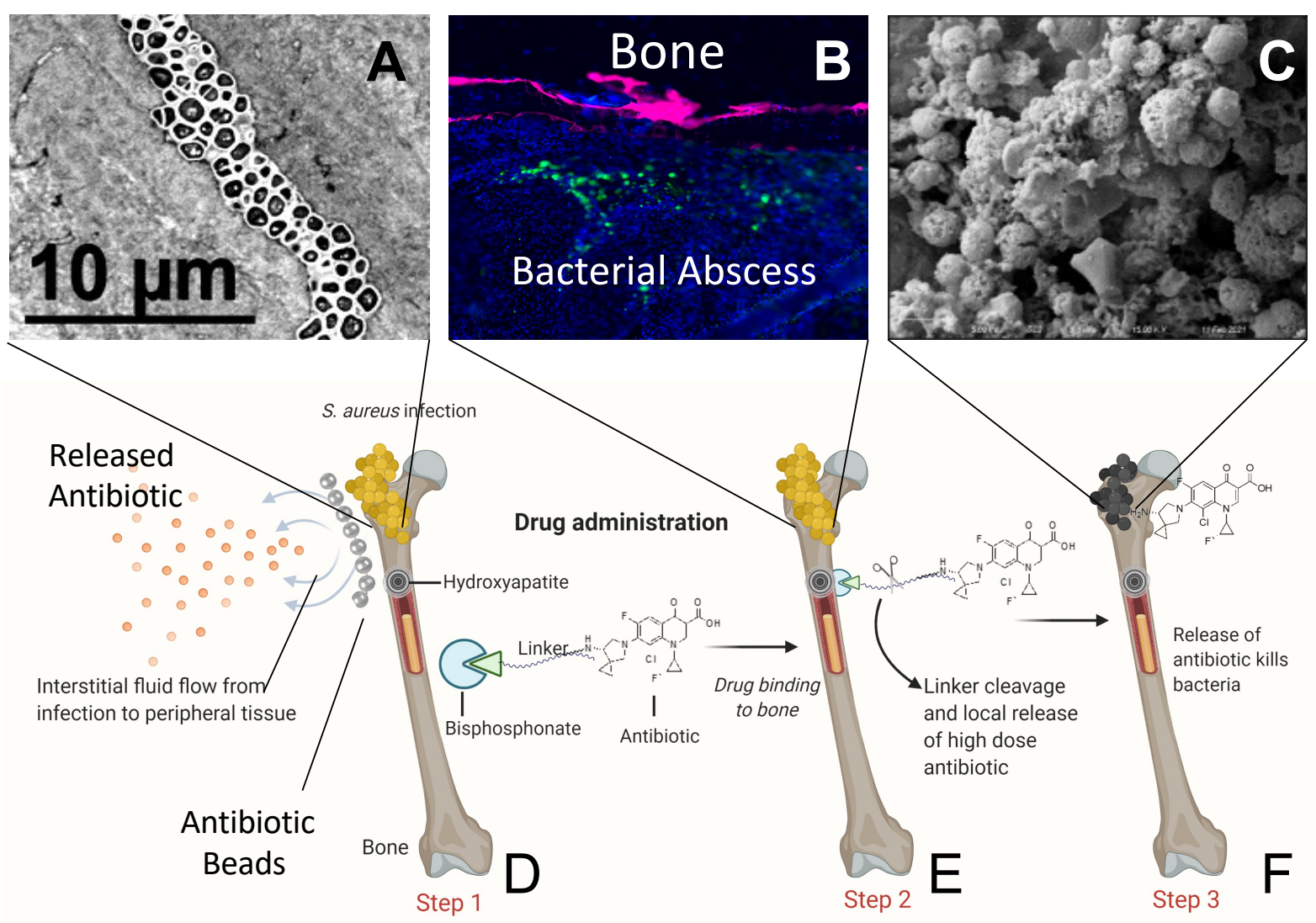

Figure 1. Schematic illustration of bone targeting bisphosphonate-conjugated antibiotic therapy: Theorized bone targeted bisphosphonate-conjugated antibiotics are designed to increase the concentration of systemic (oral or intravenous) or local (antibiotic-loaded bone cement) antibiotics above the minimum inhibitory concentration (MIC) and minimum biofilm eradication concentration (MBEC) levels in immediate proximity to planktonic and biofilm bacteria that have infected bone, (A) Transmission electron microscope archival image of S. aureus biofilm occupying a canaliculus of the OLCN; (B) Bisphosphonate labeled bone (pink) and S. aureus positive immunofluorescence labeling (green); (C) Scanning electron microscope image of dead S. aureus cocci after antibiotic treatment, which cannot be achieved by conventional methods. In this model, the infecting bacteria (e.g., S. aureus, gold clustered cocci) have colonized the bone (e.g., proximal femur) and adjacent bone and soft tissues are sheltered from conventional antibiotic therapies by interstitial fluid flow from the wound to peripheral tissues, which drives the drug away from the infection. To overcome these adverse pharmacodynamics (PD), antibiotics conjugated to an inactive bisphosphonate moiety (e.g., (2-(4-hydroxyphenyl)ethane-1,1-diyl)bis(phosphonic acid) (HPBP), blue pie with open wedge) via a linker with adequate serum stability (green wedge with organic chain) that binds with high affinity $\left(10^{-6} \mathrm{M}\right)$ to hydroxyapatite of metabolically active bone (Step 1$)(\mathrm{D})$. Activation of the accumulated bone-bound conjugated antibiotic occurs following linker cleavage via the enzymatic/acidic environment of the infected bone surface (Step 2) (E), which releases the drug to kill the bacteria (Step 3, black cocci) (F,C). For proof of concept, note in (B), the fluorescent bisphosphonate labeled bone (red) is found in immediate proximity to a bacterial abscess (green label). (See also Figure 5).

\section{Material and Methods}

\subsection{S. aureus Strains and In Vitro Culture}

Two different $S$. aureus strains were used: (1) UAMS-1, a widely used MSSA strain that was isolated from an osteomyelitis patient [33], and (2) USA300LAC [34], which is the most prevalent community-acquired MRSA strain. All strains were cultured in tryptic soy broth (TSB) media. For static biofilm formation, the bacteria were grown in 24-well plates as previously described [28].

\subsection{Animal Surgeries and AF647-ZOL Treatment}

Alexa Fluor 647 conjugated to zoledronic acid (AF647-ZOL) is a red fluorescent-BP conjugated probe that has been used to demonstrate BP-conjugated drug bone-targeting 
potential in animal models [29]. AF647-ZOL was obtained from BioVinc, LLC as a lyophilate and used as received. All in vivo experiments with mice were performed following protocols approved by the University of Rochester Committee on Animal Resources (UCAR 2019-015). The surgical approach was performed as previously described [35], in which a flat stainless steel wire (cross-section $0.2 \mathrm{~mm} \times 0.5 \mathrm{~mm}$; MicroDyne Technologies, Plainville, CT, USA) was contaminated with $10^{5} \mathrm{CFU}$ of MSSA or MRSA from an overnight culture, and surgically implanted through the tibia of six-week-old Balb/c female mice $(n=3)$ (Jackson Labs, Bar Harbor, ME, USA). One week later, the mice received an intraperitoneal injection of AF647-ZOL $(0.385 \mathrm{mg} / \mathrm{kg})$ as previously described [29], and the mice were euthanized one week later (day 14 post-op) to assess the infected tibiae via histology.

\subsection{Histology and Fluorescent Microscopy}

Infected tibiae were processed for undemineralized frozen histology. The hindlimbs were cleaned of soft tissue and fixed with gentle agitation in 10\% Neutral Buffered Formalin (NBF) for $1.5 \mathrm{~h}$ at $4{ }^{\circ} \mathrm{C}$ followed by an additional hour at room temperature. Samples were then placed in a 30\% sucrose/phosphate buffered saline (PBS) solution overnight at $4{ }^{\circ} \mathrm{C}$ prior to embedding into Cryomatrix Frozen Embedding Medium (Thermo Fisher, Houston, TX, USA). Samples were sectioned at $10 \mathrm{~mm}$ using the previously described tape transfer method and Cryofilm Type 2C [36]. Tape sections were adhered to glass slides, tissue side up, using a solution of $1 \%$ chitosan $/ 0.25 \%$ acetic acid and allowed to cure for $48 \mathrm{~h}$ at $4{ }^{\circ} \mathrm{C}$ prior to staining.

Brown-Brenn modified Gram stain to visualize Gram positive bacteria on serial sections was performed as previously described [24]. Immunofluorescent staining was performed as previously described [24], but without antigen retrieval methods. The tissue was blocked in at room temperature in 5\% normal goat serum (NGS) in 0.3\% Triton-X100 TBS for 40 mins, and then slides were incubated with polyclonal antibody for S. aureus (1:100, Invitrogen, Cat\#: PA1-7246) in 5\% NGS in 0.3\% Triton-X100 TBS at $4{ }^{\circ} \mathrm{C}$ overnight. Next, anti-rabbit FITC conjugated secondary antibody (1:400, Invitrogen, Cat\#: A-11008) in 5\% NGS in $0.3 \%$ Triton-X100 TBS was added to sections for $1 \mathrm{hr}$ at room temperature. Finally, sections were counterstained with nuclear stain DAPI and mounted with ProLong Gold Antifade Mountant (Life Technologies, Eugene, OR, USA). Stain specificity was validated by incubating with the secondary antibody only (data not shown). Slides were either imaged using a VS120 Virtual Slide Microscope (Olympus, Waltham, MA, USA) for abscess imaging or via confocal laser scanning microscopy (CLSM) for sequestra imaging. CLSM was performed using an inverted Olympus FV 1000 microscope using a $60 \times$ oil immersion objective with $0.5 \mu \mathrm{m}$ slices. Z-stack images were processed using ImageJ to create max-intensity z-projections.

\subsection{Hydroxyapatite (HA) Discs}

Test articles HA discs (3D Biotek, LLC. Bridgewater, NJ, USA) received directly from the manufacturer with sterile package. It is a bone mineral-like material disc compatible for 96 -well culture dish with diameter $\sim 5 \mathrm{~mm}$, and thickness $\sim 1.6 \mathrm{~mm}$. The quality of the manufactured HA discs was checked by means of scanning electron microscopy (SEM) as illustrated in Figure 2A-C.

\subsection{Synthesis and Characterization of BP Conjugated Antibiotics (BCAs)}

The chemical structures of sitafloxacin, tedizolid, and the various BP and HBP conjugates used in this study are described in Figure 3 (Bisphosphonate-carbamate-sitafloxacin: BCS; $\alpha$-hydroxybisphosphonate-carbamate-sitafloxacin: HBCS; Bisphosphonate-carbamatetedizolid: BCT; $\alpha$-hydroxybisphosphonate-carbamate-tedizolid: HBCT; Bisphosphonateester-tedizolid (BET)). The BPs used for conjugation are: (2-(4-hydroxyphenyl)ethane-1,1diyl)bis(phosphonic acid) (HPBP); (2-(4-aminophenyl)ethane-1,1-diyl)bis(phosphonic acid) (APBP); 4-(2,2-diphosphonoethyl)benzoic acid (CPBP); and the HBPs used for conjugations are: (1-hydroxy-2-(4-hydroxyphenyl)ethane-1,1-diyl)bis(phosphonic acid) (HPHBP); 
(2-(4-aminophenyl)-1-hydroxyethane-1,1-diyl)bis(phosphonic acid) (APHBP). All of these compounds were synthesized similarly according to procedures as originally reported in Sedghizadeh et al. [28], and Sun et al. [25]. The compounds were characterized by NMR, mass spectrometry, combustion elemental analysis and HPLC, demonstrating $>95 \%$ purity.
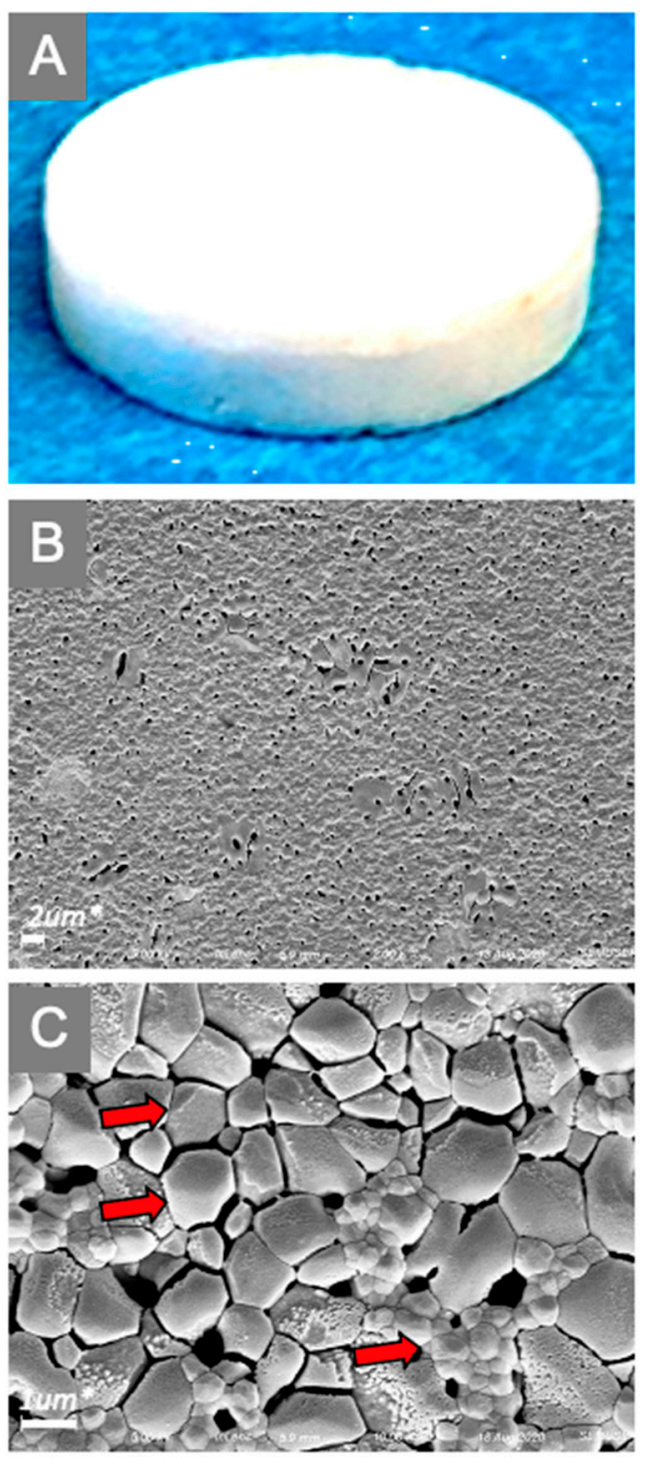

Figure 2. Surface characteristics of experimental HA disc surfaces determined by scanning electron microscope (SEM). Test articles HA discs (A) (3D Biotek, LLC. Bridgewater, NJ, USA) received directly from the manufacturer were evaluated by SEM, and representative images of the surface are shown at low magnification $(2.00 \mathrm{~K} \times)(\mathbf{B})$, and high magnification $(10.00 \mathrm{~K} \times)(\mathbf{C})$. Note the HA disc's surface has an irregular pebble-like arrangement (indicated with red arrows).

\subsection{In Vitro MSSA and MRSA Biofilm Eradication Assays}

The dose-dependent efficacy of sitafloxacin and tedizolid conjugated BP and HBP versus their parent antibiotic was assessed using an in vitro HA disc assay described in Figure 4. Briefly, $1 \mathrm{~mL}$ of tryptic soy broth (TSB) containing $10^{7}$ Colony-forming units (CFU) of a bioluminescent MSSA strain (Xen36(Luc)) or MRSA strain (USA300LAC::Luc) was added to each well of a 24-well plate, and HA discs were placed in each well and incubated for $24 \mathrm{~h}$ at $37^{\circ} \mathrm{C}$. After $24 \mathrm{~h}$, HA discs were washed three times in $1 \mathrm{~mL}$ of sterile PBS for $5 \mathrm{~min}$ in a gentle rocker shaker. Then, HA discs were incubated in 800, 400, 200, $100,50,25,10,5$, or $1 \mathrm{mg} / \mathrm{L}$ of HBCS, BCS, Sitafloxacin Hydrate, HPHBP, or HPBP, for $24 \mathrm{~h}$ at $37^{\circ} \mathrm{C}$. The discs were then rinsed to remove non-bound bacteria, and subjected to 
vigorous vortex and sonication to collect adherent bacteria from the HA discs. CFU were determined using the Miles and Misra method, in which serial dilutions were cultured on modified TSB agar plates, and quantified after $24 \mathrm{~h}$ incubation at $37^{\circ} \mathrm{C}$. This protocol was repeated using HBCT, BCT, Tedizolid, and BET with concentration of 100 and $800 \mathrm{mg} / \mathrm{L}$.

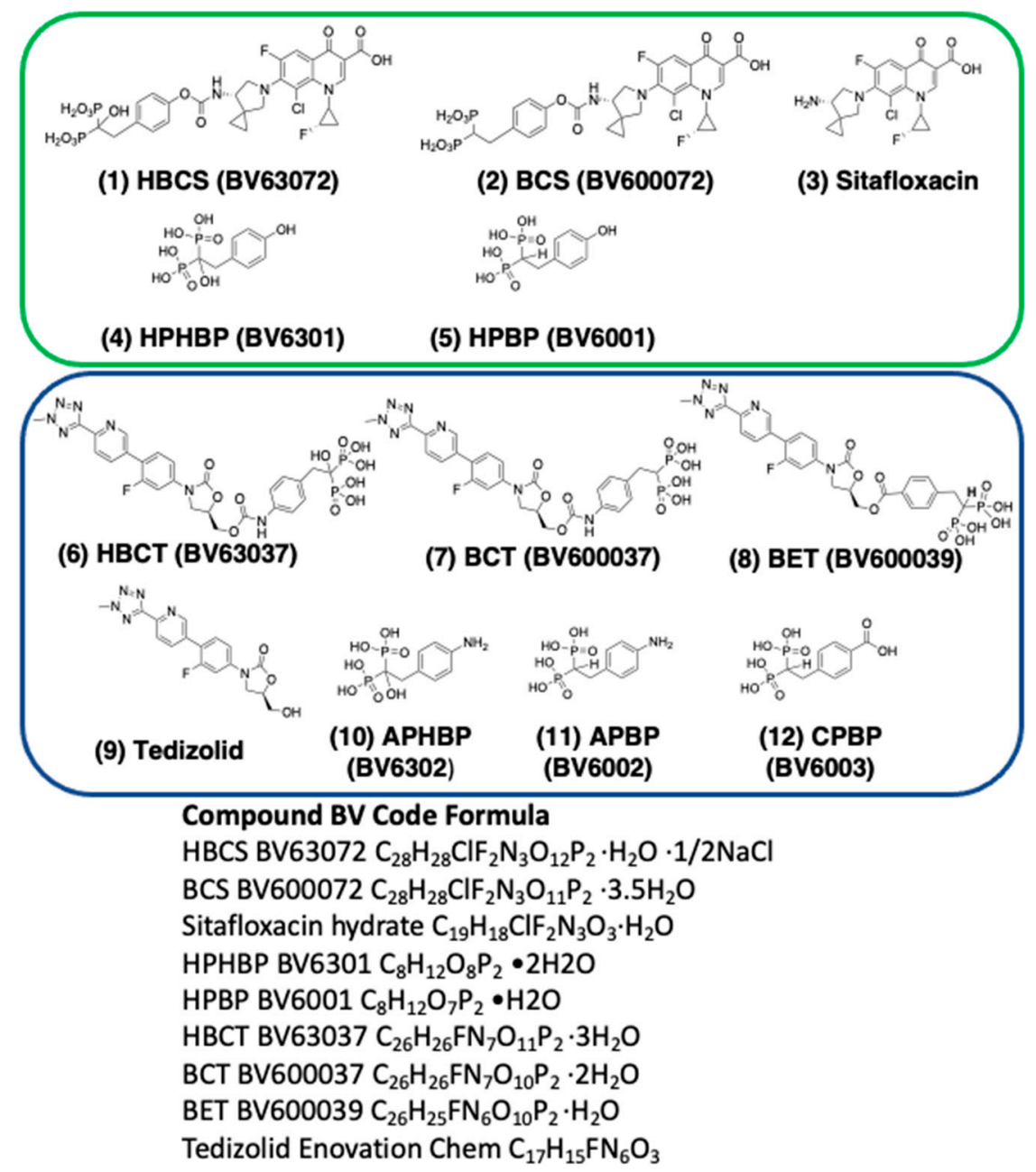

Figure 3. Molecular structure and empirical formula of antibiotics and conjugates: (1) HBCS, (2) BCS, (3) Sitafloxacin hydrate, (4) HPHBP, (5) PHBP, (6) HBCT, (7) BCT, (8) BET, (9) Tedizolid, (10) APHBP, (11) APBP, (12) CPBP were synthesized according to procedures reported by Sun et al. and Sedghizadeh et al. [28,31]. All compounds were characterized by NMR, mass spec, elemental analyses and HPLC demonstrating high purity. On cleavage of the carbamate linkage of (1), (2), (6), (7), the released bisphosphonates (4), (5), (10), (11) and $\mathrm{CO}_{2}$ are pharmacologically inactive components. Since cleavage of the linker and release of antibiotic occurs mainly at sites of higher bone resorption caused by osteoclastic or bacterial osteolysis, extremely high local concentrations of antibiotic are generated beneath or in the proximity of infections on bone surfaces. Conjugate (8) utilizes an ester linkage which appears to cleave more readily than carbamate comparators in vitro and will be compared for efficacy in vivo.

\subsection{Scanning Electron Microscopy (SEM)}

SEM was performed as previously described [35]. Briefly, the HA disks from the in vitro studies were placed into 24 well plates, fixed in $2.5 \%$ glutaraldehyde $/ 4 \%$ paraformaldehyde in $0.1 \mathrm{M}$ cacodylate overnight and post-fixed in buffered $1 \%$ osmium tetroxide. A pipet tip was placed against the wall of the wells, for fluid exchange or removal to reduce disruption of biofilm during dehydration in a graded series of ethanol to $100 \%$. The disks were then critically point dried, mounted onto aluminum 
stubs and sputter coated with gold prior to imaging using a Zeiss Auriga FE SEM. Three SEM micrographs per sample group were randomly chosen for descriptive analysis.

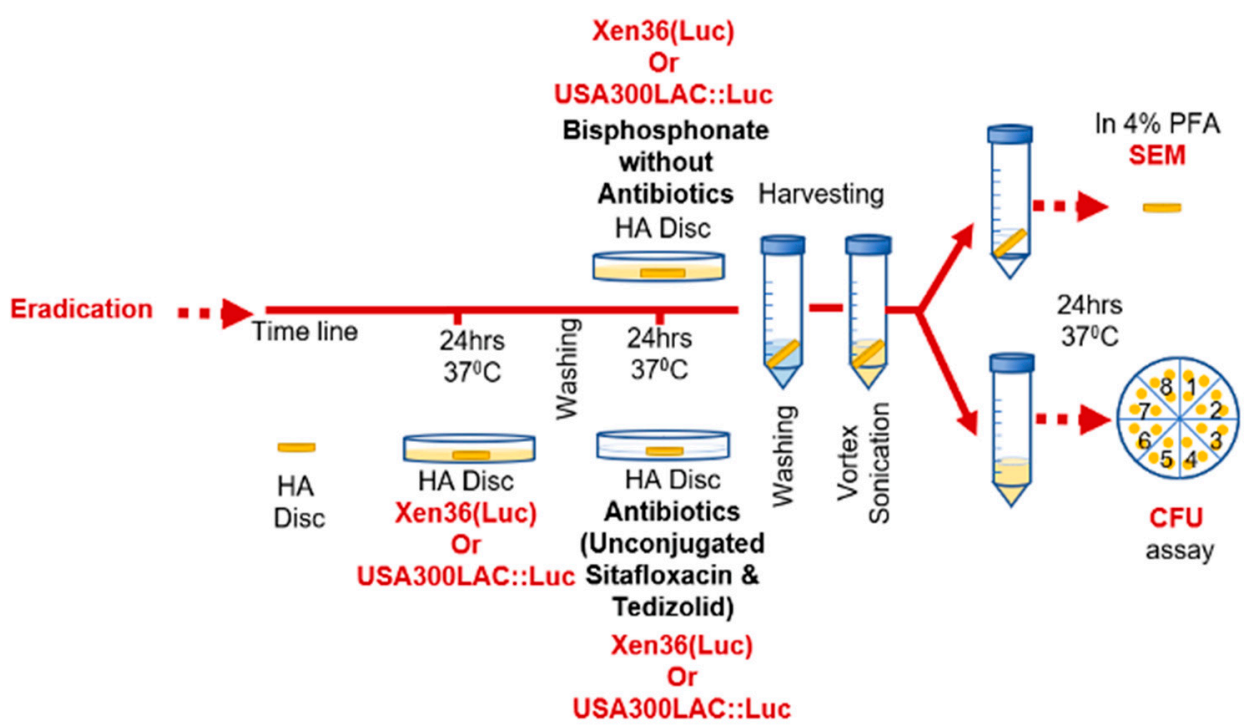

Figure 4. The experimental design of the antibiotic pretreatment to assess inhibition or eradication of biofilm formation on HA discs. $1 \mathrm{~mL}$ of tryptic soy broth (TSB) containing $10^{7}$ Colony-forming units (CFU) of a bioluminescent MSSA strain (Xen36(Luc)) or MRSA strain (USA300LAC::Luc) was added to each well of a 24-well plate, and HA discs were placed in each well and incubated for $24 \mathrm{~h}$ at $37^{\circ} \mathrm{C}$ After $24 \mathrm{~h}$, HA discs were washed three times in $1 \mathrm{~mL}$ of sterile PBS for $5 \mathrm{~min}$ in a gentle rocker shaker. Then HA discs were incubated in 800, 400, 200, 100, 50, 25, 10, 5, or $1 \mathrm{mg} / \mathrm{L}$ of HBCS, BCS, Sitafloxacin Hydrate, HPHBP, or HPBP, for $24 \mathrm{~h}$ at $37^{\circ} \mathrm{C}$. The discs were then rinsed to remove non-bound bacteria, and subjected to vigorous vortex and sonication to collect adherent bacteria from the HA discs. CFUs were quantified via serial dilutions cultured on modified TSB agar plates at $37^{\circ} \mathrm{C}$ for $24 \mathrm{~h}$. This protocol was repeated using HBCT, BCT, Tedizolid and BET, HPHBP, or HPBP with concentration of 800 and $100 \mathrm{mg} / \mathrm{L}$.

\section{Results}

\subsection{Systemically Delivered AF647-ZOL Accumulates at the Bone-Bacteria Interface}

To assess the feasibility of BP and HBP-conjugated antibiotic "target and release" therapy for chronic osteomyelitis, we performed a pilot study to assess the in vivo labeling efficiency of a BP-conjugated fluorescent probe (AF647-ZOL) in S. aureus infected mouse tibiae. Consistent with prior reports [29], the results demonstrated with a fluorophore conjugated BP probe, that bisphosphonates efficiently labels all modeling (growth plate) and remodeling (endosteal and periosteal) bone surfaces in the growing animals. In particular, label was observed in higher concentrations at the highest bone turnover sites (Figure 5A). Moreover, Brown-Brenn staining of Staphylococcus abscess communities (SAC), immunohistochemistry, and SEM for S. aureus confirmed AF647-ZOL incorporation on cortical bone surfaces in immediate proximity to the bacteria (Figure 5B-F).

\subsection{In Vitro Biofilm Eradication Efficacy of Conjugated BP and HBP Conjugated Sitafloxacin and Tedizolid}

As an initial screen towards a lead candidate drug, we assessed the ability of BP and HBP conjugated sitafloxacin and tedizolid, versus their parental antibiotic controls, using an established in vitro biofilm eradication assay, as described in Figure 4. SEM analyses of MRSA static biofilms on the HA discs confirmed the cytolytic activity of the conjugated antibiotics, as evidence by the striking appearance of the shrunken, porous, decomposing bacteria in the drug treated samples versus the BP controls (Figure 6). Quantitative analyses confirmed the great potency of both sitafloxacin conjugates (O-phenylcarbamate linkage) on MSSA static biofilm, and no CFU could be recovered even at the lowest dose $(1 \mathrm{mg} / \mathrm{L})$ 

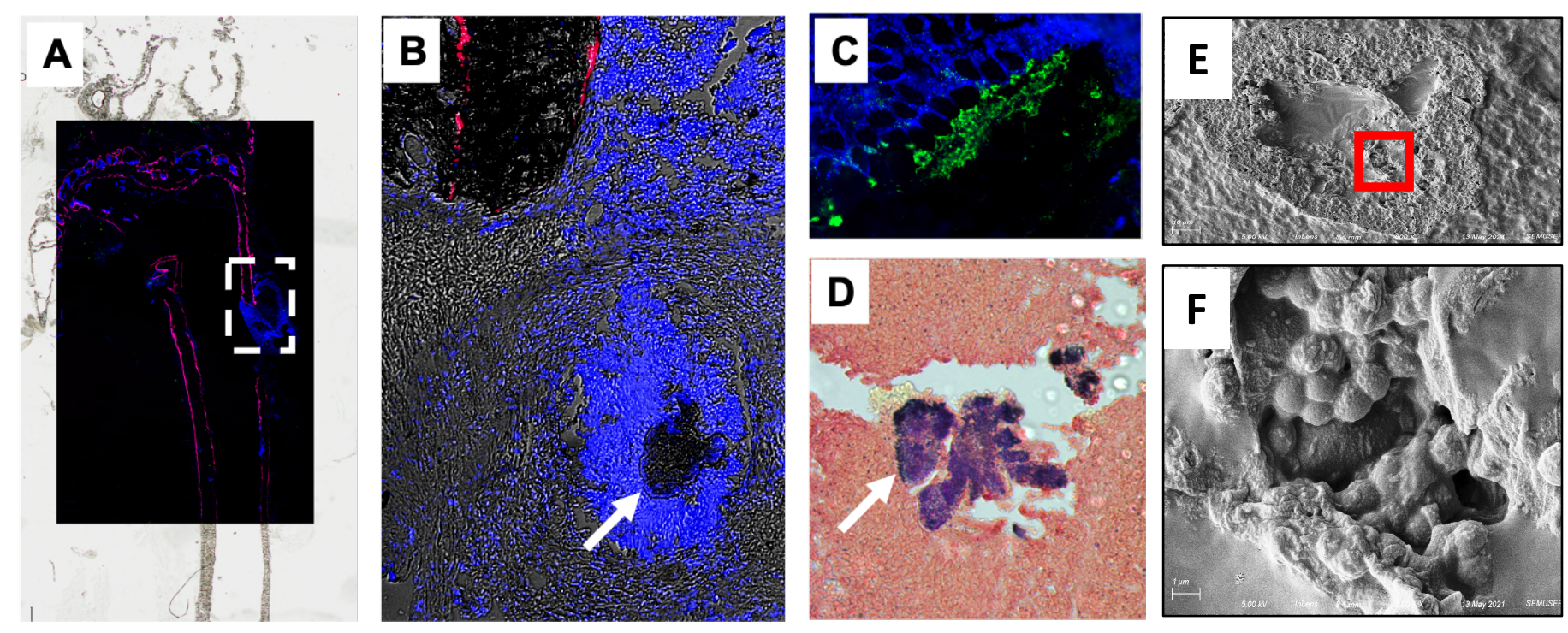

Figure 5. Bone targeted drug labeling of cortical bone proximal to S. aureus infection. To illustrate the potential of bone targeted antibiotics, we performed a pilot study in which mice received a transtibial pin contaminated with $10^{5} \mathrm{CFU}$ of MRSA [37], and then received an intraperitoneal injection of AF647-Zoledronate (AF647-ZOL) 7 days later [37]. Mice were euthanized on day 14 post-op, and infected tibiae were processed for undemineralized frozen histology. (A) Superimposed darkfield fluorescent image obtained at $4 \times$ on top of bright field image of the tibia highlighting the host soft tissue (blue from DAPI stain), and AF647-ZOL labeled cortical bone (red). (B) The region of interest (dashed line box in A shown in B at $20 \times$ ) contains a bacterial abscess in immediate proximity to the labeled bone, which was confirmed to be a Staphylococcus abscess community (SAC) (arrow) via immunohistochemistry (green) (C) and Brown-Brenn staining (D) of serial sections, as we have previously described [37]. (E) Scanning electron microscopy image from an adjacent slide to D of the same SAC at $800 \times$. (F) Higher magnification of the red box in $\mathrm{E}$ at $8000 \times$ magnification confirms clusters of $S$. aureus cocci known to reside in SACs that are resistant to standard of care antibiotic therapy. 

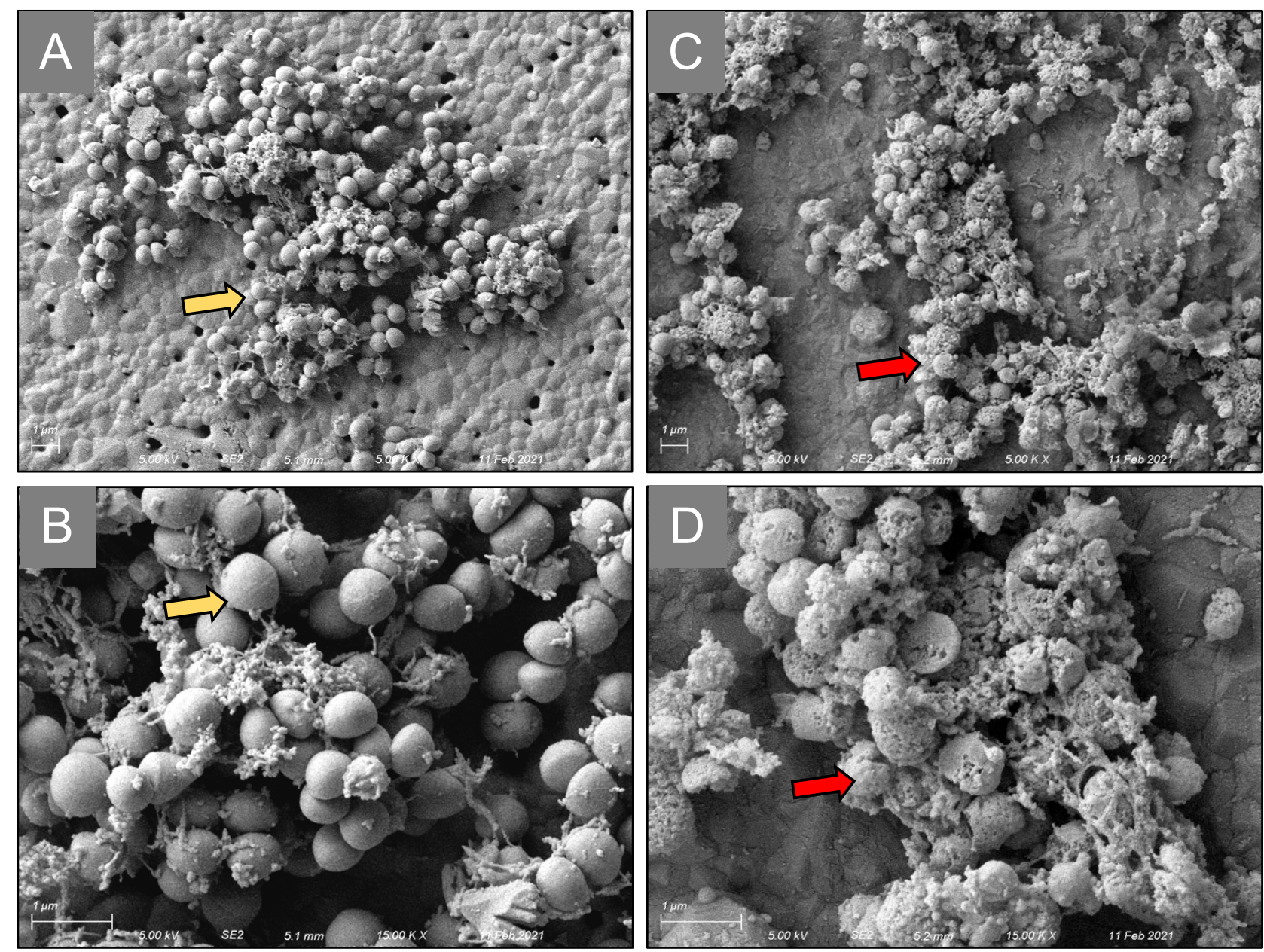

Figure 6. Scanning electron microscopy imaging of $S$. aureus exposed to HBCS antibiotics. Static MRSA biofilms were generated on HA disks and were untreated $(\mathbf{A}, \mathbf{B})$ or treated with HBCS as described in Figure 4. Representative SEM images are shown to illustrate the normal $S$. aureus cells (yellow arrows) from mid-to-late logarithmic growth phase on the HA disc surface at low magnification $(5.00 \mathrm{~K} \times)(\mathbf{A})$, and high magnification $(15.00 \mathrm{~K} \times)(\mathbf{B})$. In contrast, HBCS treated MRSA static biofilm display a striking appearance of dead bacteria with significant cell wall damage (red arrows) as illustrated at low $(5.00 \mathrm{~K} \times)(\mathbf{C})$, and high magnification $(15.00 \mathrm{~K} \times)(\mathbf{D})$. 


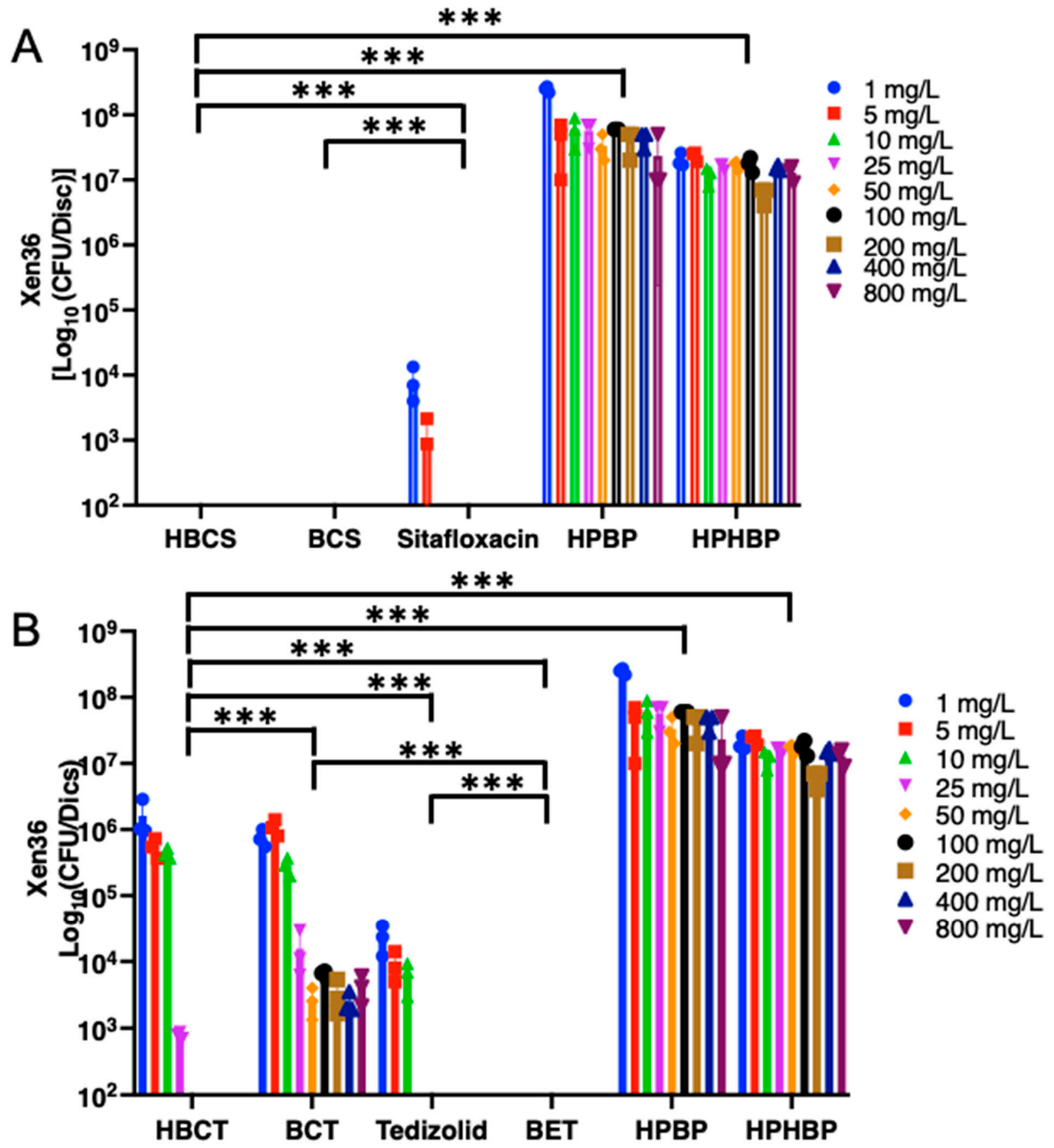

Figure 7. In vitro efficacy of BP conjugated sitafloxacin and tedizolid bone-targeted compounds in MSSA static biofilm assay. Xen36 (MSSA strain) static biofilms were grown on HA discs, and treated with the indicated concentration of (A) BP/HBP-sitafloxacin conjugates and Sitafloxacin or (B) BP/HBP-tedizolid conjugates and tedizolid, and the control of HPBP or HPHBP and efficacy was quantified via CFU assay as described in Figure 4. Data are presented as the mean $+/-$ $\mathrm{SD}\left(\mathrm{N}=3{ }^{* * *} p>0.001\right.$ via two-way ANOVA with Tukey's Multiple). 


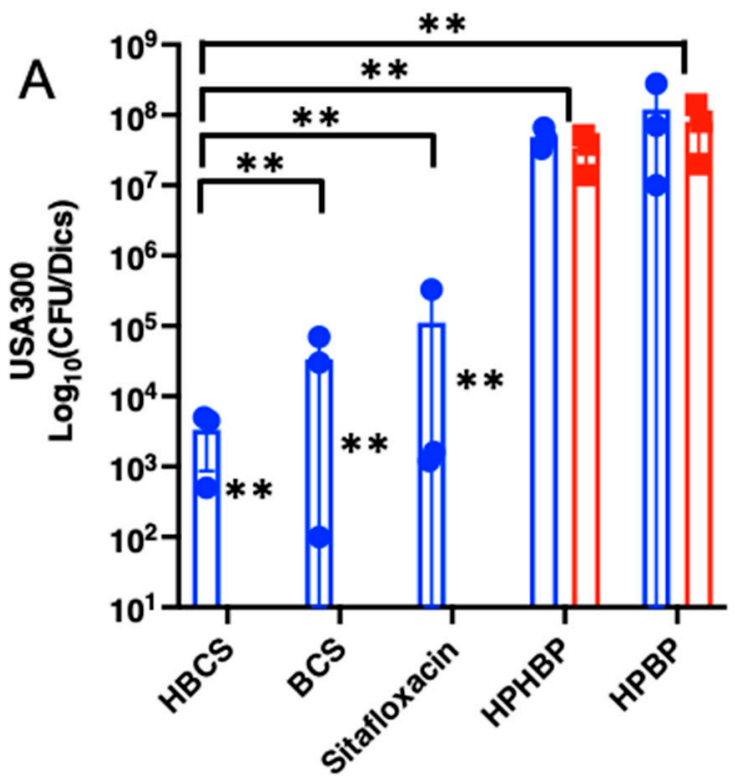

- $100 \mathrm{mg} / \mathrm{L}$

800mg/L

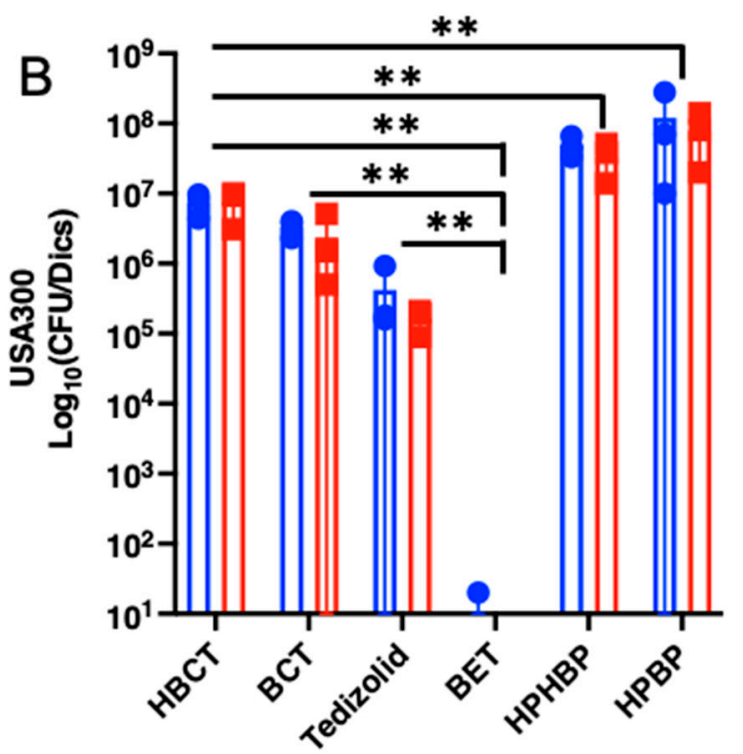

$100 \mathrm{mg} / \mathrm{L}$ $800 \mathrm{mg} / \mathrm{L}$

Figure 8. In vitro efficacy of BP conjugated sitafloxacin and tedizolid bone-targeted compounds in MRSA static biofilm assay. USA300 (MRSA strain) static biofilms were grown on HA discs, and treated with the indicated concentration of (A) BP/HBP-sitafloxacin conjugates and sitafloxacin or (B) BP/HBP-tedizolid conjugates and tedizolid, and the control of HPBP or HPHBP and efficacy was quantified via CFU assay as described in Figure 3. Data are presented as the mean $+/-\mathrm{SD}(\mathrm{N}=3$; ** $p>0.05$ via Two-Way ANOVA with Tukey's Multiple).

\section{Discussion}

As a result of its great density from calcification, bone has unique pharmacodynamic challenges for drug targeting, including antibiotic treatments. While the major clinical challenges in curing chronic osteomyelitis are well known, the futility of so called "local" antibiotic therapy achieved from placing a high concentration of drug proximal to the infection in ALBC has become a great topic of debate, as there are no clinical studies that have demonstrated efficacy over systemic antibiotic therapy alone, and the costs of ALBC have been called into question [23]. Moreover, the seminal in vivo rabbit study of Giers et al. [39], which demonstrated that MRI contrast agents similar in size and solubility to common antimicrobials mixed with bone cement are transported away from the bone lesion, suggests that interstitial fluid convection thwarts such "local" antibiotic therapies, 
as illustrated in Figure 1. Given these issues and the lack of success in treating S. aureus bone infection, new approaches are evidently needed to target antibiotics more effectively to bone infection sites.

Bisphosphonates (BP) are a drug class that were specifically developed to target bone with great specificity and minimal side effects on soft tissues [25]. Salient examples are the potent nitrogen-containing bisphosphonates used for the treatment of bone diseases, such as osteoporosis and osteolysis related to metastatic bone [40]. The bone-binding affinity of a BP is predominantly determined by its two geminal phosphonate groups (P-C-P), which form strong bi- and tri-dentate interactions with calcium ions [41,42]. Several different types of bone-targeting drug conjugate candidates have been developed by linking them to BP (e.g., bortezomib [43,44]), and the subject has been extensively reviewed $[45,46]$. We have sought to create a bone-targeted antibiotic conjugate that could achieve sustained concentrations of drug well above the MBEC at the site of bone infection. Of note, this approach is expected to overcome the challenge of interstitial fluid convection following systemic administration (Figure 1). In support of this concept, we show for the first time that systemic administration of a BP-conjugated fluorophore (AF647-ZOL) probe specifically labels the cortical surface of bone in immediate proximity to $S$. aureus bacteria during chronic osteomyelitis where osteolysis is prolific (Figure 5). As this is a prelude to formal in vivo proof of concept studies with both male and female mice to demonstrate the safety, pharmacokinetics, and efficacy of BP and HBP-conjugated sitafloxacin and tedizolid for the treatment of $S$. aureus osteomyelitis, future studies aimed at assessing prophylaxis, and multiple dosing regimens are planned to assess the potential of this approach to reduce the risks of infection, and if the bone targeted drug accumulates adequately over time. In addition to BP, other bone mineral seeking agents have also been tested preclinically with moderate success. $[47,48]$. Recently, Rotman et al. showed that microspheres coated with biodegradable polyesters such as poly (aspartic acid) and poly ( $\varepsilon$-caprolactone) displayed enhanced bone targeting properties and sustained antibiotics release [49].

Although our initial success with BP-conjugated ciprofloxacin is promising [28], we acknowledge that fluoroquinolones suffer from reduced activity against established biofilms, which is particularly true for virulent strains of $S$. aureus $[30,31]$. Therefore, this study examined antibiotic conjugates designed to exhibit more effective biofilm eradication. Although we could have used antibiotics usually commonly used to treat bone infection (i.e., gentamicin), we chose to investigate BP-sitafloxacin conjugates on the basis of on our prior FDA-approved drug library screen for bactericidal activity against $S$. aureus SCV. While four library members (daunorubicin, ketoconazole, rifapentine, and sitafloxacin) exhibited potent SCV bactericidal activity against a stable $S$. aureus SCV, only sitafloxacin was potent against MSSA and MRSA established biofilms [50]. Moreover, we showed in murine infected bone defect models that incorporating rifampin and sitafloxacin into 3D-printed calcium-phosphate resorbable scaffold was more antimicrobial and osteoconductive in a single-stage revision versus conventional gentamicin ALBC in a two-stage revision [51]. We chose tedizolid as an alternative antibiotic based on similar biofilm eradication activity [52]. As expected, the O-phenyl carbamate sitafloxacin-conjugated BP and HBP demonstrated substantial biofilm eradication potential against prototypic MSSA and MRSA stains (Figures 7 and 8). Importantly, the lack of efficacy observed with $N$-phenyl carbamate linked tedizolid-conjugated BP and HBP, which was overcome by introducing a more labile ester linker (BET), supports the value of our "target and release" local drug delivery strategy (Figure 7B) and warrants future extension to in vivo validation studies.

While these preliminary studies are promising, they have several limitations that should be noted, including the small number of replicates $(n=3)$, which need to be repeated with larger numbers of samples and time courses. We also need to commence in vivo animal studies to assess the potential clinical relevance of the biofilm eradiation activity we observed with these novel compounds. Several of these studies are planned, and the potential of this technology will become known in the near future. 
Author Contributions: Conceptualization, E.M.S., C.X., F.H.E., and S.S.; Data curation, E.A.-S., Y.P., J.W., J.H.J., K.L.d.M.B., E.M., Y.M., G.M., P.C., X.E.H., S.S., E.M.S., and C.X.; Formal analysis, E.A.-S., J.H.J., K.L.d.M.B., E.M., Y.M., P.C., X.E.H., F.H.E., S.S., E.M.S., and C.X.; Funding acquisition, F.H.E., S.S., E.M.S. and C.X.; Investigation, E.A.-S., Y.P., J.W., J.H.J., K.L.d.M.B., Y.M., F.H.E., S.S., E.M.S. and C.X.; Methodology, E.A.-S., Y.P., J.W., J.H.J., K.L.d.M.B., E.M., Y.M., P.C., X.E.H., C.E.M., F.H.E., S.S., E.M.S., and C.X.; Project administration, E.M.S., C.X., F.H.E., S.S.; Supervision, E.M.S., C.X., F.H.E., S.S.; Validation, E.A.-S., Y.P., F.H.E., S.S., E.M.S., and C.X.; Writing-original draft, E.A.-S., Y.P., J.W., J.H.J., K.L.d.M.B., E.M., Y.M., G.M., P.C., X.E.H., C.E.M., F.H.E., S.S., E.M.S., and C.X.; Writing-review and editing, E.M.S., C.X., F.H.E., and S.S. All authors have read and agreed to the published version of the manuscript.

Funding: This research was funded by National Institutes of Health, Grant numbers: R44AI125060, P30 AR069655 and P50 AR072000.

Institutional Review Board Statement: The study was conducted according to the guidelines of the Declaration of Helsinki, and approved by the University of Rochester Committee on Animal Resources (UCAR 2019-015, 5 September 2019 approval).

Data Availability Statement: The data presented in this study are available on request from the corresponding authors. The data are not publicly available due to patent restrictions.

Acknowledgments: This work was supported by grants from the National Institutes of Health (SBIR R44 AI125060, NIAMS P50 AR072000 and NIAMS P30 AR069655). We would like to thank the members of the Histology, Biochemistry and Molecular Imaging Core in the Center for Musculoskeletal Research. Additionally, we would like to thank the Confocal and Conventional Microscopy Core at the University of Rochester, Rochester, NY, USA.

Conflicts of Interest: CEM, SS and FHE hold equity in BioVinc, LLC (Pasadena, CA) which sponsored this research. CEM is a consultant for BioVinc LLC. PC, EH, CEM, SS and FHE are inventors on patents related to this work.

\section{References}

1. Schwarz, E.M.; Parvizi, J.; Gehrke, T.; Aiyer, A.; Battenberg, A.; Brown, S.A.; Callaghan, J.J.; Citak, M.; Egol, K.; Garrigues, G.E.; et al. 2018 International Consensus Meeting on Musculoskeletal Infection: Research Priorities from the General Assembly Questions. J. Orthop. Res. 2019, 37, 997-1006. [CrossRef]

2. Auerbach, A. Healthcare Quality Measurement in Orthopaedic Surgery: Current State of the Art. Clin. Orthop. Relat. Res. 2009, 467, 2542-2547. [CrossRef]

3. Aslam, S.; Darouiche, R.O. Prosthetic Joint Infections. Curr. Infect. Dis. Rep. 2012, 14, 551-557. [CrossRef] [PubMed]

4. Azzam, K.; McHale, K.; Austin, M.; Purtill, J.J.; Parvizi, J. Outcome of a Second Two-stage Reimplantation for Periprosthetic Knee Infection. Clin. Orthop. Relat. Res. 2009, 467, 1706-1714. [CrossRef] [PubMed]

5. Ghanem, E.; Azzam, K.; Seeley, M.; Joshi, A.; Parvizi, J. Staged revision for knee arthroplasty infection: What is the role of serologic tests before reimplantation? Clin. Orthop. Relat. Res. 2009, 467, 1699-1705. [CrossRef] [PubMed]

6. Parvizi, J.; Azzam, K.; Ghanem, E.; Austin, M.S.; Rothman, R.H. Periprosthetic Infection Due to Resistant Staphylococci: Serious Problems on the Horizon. Clin. Orthop. Relat. Res. 2009, 467, 1732-1739. [CrossRef]

7. Ferry, T.; Uçkay, I.; Vaudaux, P.; François, P.; Schrenzel, J.; Harbarth, S.; Laurent, F.; Bernard, L.; Vandenesch, F.; Etienne, J.; et al. Risk factors for treatment failure in orthopedic device-related methicillin-resistant Staphylococcus aureus infection. Eur. J. Clin. Microbiol. Infect. Dis. 2009, 29, 171-180. [CrossRef]

8. Salgado, C.D.; Dash, S.; Cantey, J.R.; Marculescu, C.E. Higher Risk of Failure of Methicillin-resistant Staphylococcus aureus Prosthetic Joint Infections. Clin. Orthop. Relat. Res. 2007, 461, 48-53. [CrossRef]

9. Masters, E.A.; Trombetta, R.P.; de Mesy Bentley, K.L.; Boyce, B.F.; Gill, A.L.; Gill, S.R.; Nishitani, K.; Ishikawa, M.; Morita, Y.; Ito, H.; et al. Evolving concepts in bone infection: Redefining "biofilm", "acute vs. chronic osteomyelitis", "the immune proteome" and "local antibiotic therapy". Bone Res. 2019, 7, 20. [CrossRef]

10. Schwarz, E.M.; McLaren, A.C.; Sculco, T.P.; Brause, B.; Bostrom, M.; Kates, S.L.; Parvizi, J.; Alt, V.; Arnold, W.V.; Carli, A.; et al. Adjuvant antibiotic-loaded bone cement: Concerns with current use and research to make it work. J. Orthop. Res. 2021, 39, 227-239. [CrossRef]

11. Buchholz, H.W.; Elson, R.A.; Heinert, K. Antibiotic-loaded acrylic cement: Current concepts. Clin. Orthop. Relat. Res. 1984, 190, 96-108. [CrossRef]

12. Parvizi, J.; Gehrke, T.; Mont, M.A.; Callaghan, J.J. Introduction: Proceedings of International Consensus on Orthopedic Infections. J. Arthroplast. 2019, 34, S1-S2. [CrossRef] 
13. Saeed, K.; McLaren, A.C.; Schwarz, E.M.; Antoci, V.; Arnold, W.V.; Chen, A.F.; Clauss, M.; Esteban, J.; Gant, V.; Hendershot, E.; et al. 2018 International consensus meeting on musculoskeletal infection: Summary from the biofilm workgroup and consensus on biofilm related musculoskeletal infections. J. Orthop. Res. 2019, 37, 1007-1017. [CrossRef] [PubMed]

14. Barberán, J. Management of infections of osteoarticular prosthesis. Clin. Microbiol. Infect. 2006, 12, 93-101. [CrossRef]

15. Chen, A.F.; Parvizi, J. Antibiotic-Loaded Bone Cement and Periprosthetic Joint Infection. J. Autom. Inf. Sci. 2014, 24, 89-97. [CrossRef] [PubMed]

16. Moojen, D.J.F.; Hentenaar, B.; Vogely, H.C.; Verbout, A.J.; Castelein, R.M.; Dhert, W. In Vitro Release of Antibiotics from Commercial PMMA Beads and Articulating Hip Spacers. J. Arthroplast. 2008, 23, 1152-1156. [CrossRef]

17. Sultan, A.A.; Samuel, L.; Umpierrez, E.; Swiergosz, A.; Rabin, J.; Mahmood, B.; Mont, M.A. Routine use of commercial antibioticloaded bone cement in primary total joint arthroplasty: A critical analysis of the current evidence. Ann. Transl. Med. 2019, 7, 73. [CrossRef] [PubMed]

18. De Mesy Bentley, K.L.; MacDonald, A.; Schwarz, E.M.; Oh, I. Chronic Osteomyelitis with Staphylococcus aureus Deformation in Submicron Canaliculi of Osteocytes: A Case Report. JBJS Case Connect. 2018, 8, e8. [CrossRef] [PubMed]

19. De Mesy Bentley, K.L.; Trombetta, R.; Nishitani, K.; Bello-Irizarry, S.N.; Ninomiya, M.; Zhang, L.; Chung, H.L.; McGrath, J.L.; Daiss, J.L.; Awad, H.A.; et al. Evidence of Staphylococcus Aureus Deformation, Proliferation, and Migration in Canaliculi of Live Cortical Bone in Murine Models of Osteomyelitis. J. Bone Miner. Res. 2017, 32, 985-990. [CrossRef] [PubMed]

20. Alder, K.; Lee, I.; Munger, A.M.; Kwon, H.-K.; Morris, M.T.; Cahill, S.V.; Back, J.; Yu, K.E.; Lee, F.Y. Intracellular Staphylococcus aureus in bone and joint infections: A mechanism of disease recurrence, inflammation, and bone and cartilage destruction. Bone 2020, 141, 115568. [CrossRef]

21. Zoller, S.D.; Hegde, V.; Burke, Z.D.C.; Park, H.Y.; Ishmael, C.R.; Blumstein, G.W.; Sheppard, W.; Hamad, C.; Loftin, A.H.; Johansen, D.O.; et al. Evading the host response: Staphylococcus "hiding" in cortical bone canalicular system causes increased bacterial burden. Bone Res. 2020, 8, 43. [CrossRef]

22. Muthukrishnan, G.; Masters, E.; Daiss, J.L.; Schwarz, E.M. Mechanisms of Immune Evasion and Bone Tissue Colonization That Make Staphylococcus aureus the Primary Pathogen in Osteomyelitis. Curr. Osteoporos. Rep. 2019, 17, 395-404. [CrossRef]

23. Veis, D.J.; Cassat, J.E. Infectious Osteomyelitis: Marrying Bone Biology and Microbiology to Shed New Light on a Persistent Clinical Challenge. J. Bone Miner. Res. 2021, 36, 636-643. [CrossRef] [PubMed]

24. Masters, E.A.; de Mesy Bentley, K.L.; Gill, A.L.; Hao, S.P.; Galloway, C.A.; Salminen, A.T.; Guy, D.R.; McGrath, J.L.; Awad, H.A.; Gill, S.R.; et al. Identification of Penicillin Binding Protein 4 (PBP4) as a critical factor for Staphylococcus aureus bone invasion during osteomyelitis in mice. PLoS Pathog. 2020, 16, e1008988. [CrossRef] [PubMed]

25. Sun, S.; Tao, J.; Sedghizadeh, P.P.; Cherian, P.; Junka, A.F.; Sodagar, E.; Xing, L.; Boeckman, R.K.; Srinivasan, V.; Yao, Z.; et al. Bisphosphonates for delivering drugs to bone. Br. J. Pharmacol. 2021, 178, 2008-2025. [CrossRef] [PubMed]

26. Herczegh, P.; Buxton, T.B.; McPherson, J.C., 3rd; Kovacs-Kulyassa, A.; Brewer, P.D.; Sztaricskai, F.; Stroebel, G.G.; Plowman, K.M.; Farcasiu, D.; Hartmann, J.F. Osteoadsorptive bisphosphonate derivatives of fluoroquinolone antibacterials. J. Med. Chem. 2002, 45, 2338-2341. [CrossRef]

27. Buxton, T.B.; Walsh, D.S.; Harvey, S.B.; McPherson, J.C., 3rd; Hartmann, J.F.; Plowman, K.M. Bisphosphonate-ciprofloxacin bound to Skelite is a prototype for enhancing experimental local antibiotic delivery to injured bone. Br. J. Surg. 2004, 91, 1192-1196. [CrossRef] [PubMed]

28. Sedghizadeh, P.P.; Sun, S.; Junka, A.F.; Richard, E.; Sadrerafi, K.; Mahabady, S.; Bakhshalian, N.; Tjokro, N.; Bartoszewicz, M.; Oleksy, M.; et al. Design, Synthesis, and Antimicrobial Evaluation of a Novel Bone-Targeting Bisphosphonate-Ciprofloxacin Conjugate for the Treatment of Osteomyelitis Biofilms. J. Med. Chem. 2017, 60, 2326-2343. [CrossRef]

29. Sun, S.; Blazewska, K.; Kadina, A.P.; Kashemirov, B.A.; Duan, X.; Triffitt, J.T.; Dunford, J.; Russell, R.G.G.; Ebetino, F.H.; Roelofs, A.J.; et al. Fluorescent Bisphosphonate and Carboxyphosphonate Probes: A Versatile Imaging Toolkit for Applications in Bone Biology and Biomedicine. Bioconjug. Chem. 2016, 27, 329-340. [CrossRef]

30. Amorena, B.; Gracia, E.; Monzón, M.; Leiva, J.; Oteiza, C.; Pérez, M.; Alabart, J.L.; Hernández-Yago, J. Antibiotic susceptibility assay for Staphylococcus aureus in biofilms developed in vitro. J. Antimicrob. Chemother. 1999, 44, 43-55. [CrossRef]

31. Melchior, M.B.; Fink-Gremmels, J.; Gaastra, W. Comparative Assessment of the Antimicrobial Susceptibility of Staphylococcus aureus Isolates from Bovine Mastitis in Biofilm Versus Planktonic Culture. J. Veter Med. Ser. B 2006, 53, 326-332. [CrossRef] [PubMed]

32. Olson, M.E.; Ceri, H.; Morck, D.W.; Buret, A.G.; Read, R.R. Biofilm bacteria: Formation and comparative susceptibility to antibiotics. Can. J. Veter Res. Rev. Can. Rech. Veter 2002, 66, 86-92.

33. Gillaspy, A.F.; Hickmon, S.G.; Skinner, R.A.; Thomas, J.R.; Nelson, C.L.; Smeltzer, M.S. Role of the accessory gene regulator (agr) in pathogenesis of staphylococcal osteomyelitis. Infect. Immun. 1995, 63, 3373-3380. [CrossRef] [PubMed]

34. Kourbatova, E.V.; Halvosa, J.S.; King, M.D.; Ray, S.M.; White, N.; Blumberg, H.M. Emergence of community-associated methicillinresistant Staphylococcus aureus USA 300 clone as a cause of health care-associated infections among patients with prosthetic joint infections. Am. J. Infect. Control 2005, 33, 385-391. [CrossRef]

35. Nishitani, K.; Sutipornpalangkul, W.; de Mesy Bentley, K.L.; Varrone, J.J.; Bello-Irizarry, S.N.; Ito, H.; Matsuda, S.; Kates, S.L.; Daiss, J.L.; Schwarz, E.M. Quantifying the natural history of biofilm formation in vivo during the establishment of chronic implant-associated Staphylococcus aureus osteomyelitis in mice to identify critical pathogen and host factors. J. Orthop. Res. 2015, 33, 1311-1319. [CrossRef] 
36. Ushiku, C.; Adams, D.J.; Jiang, X.; Wang, L.; Rowe, D.W. Long bone fracture repair in mice harboring GFP reporters for cells within the osteoblastic lineage. J. Orthop. Res. 2010, 28, 1338-1347. [CrossRef] [PubMed]

37. Ghosh, A.K.; Brindisi, M. Organic Carbamates in Drug Design and Medicinal Chemistry. J. Med. Chem. 2015, 58, 2895-2940. [CrossRef]

38. Lawson, M.A.; Xia, Z.; Barnett, B.L.; Triffitt, J.T.; Phipps, R.J.; Dunford, J.E.; Locklin, R.M.; Ebetino, F.H.; Russell, R.G.G. Differences between bisphosphonates in binding affinities for hydroxyapatite. J. Biomed. Mater. Res. Part B Appl. Biomater. 2009, 92, 149-155. [CrossRef] [PubMed]

39. Giers, M.B.; McLaren, A.C.; Schmidt, K.J.; Caplan, M.R.; McLemore, R. Distribution of molecules locally delivered from bone cement. J. Biomed. Mater. Res. Part B Appl. Biomater. 2014, 102, 806-814. [CrossRef]

40. Pazianas, M.; Cooper, C.; Ebetino, F.H.; Russell, R.G. Long-term treatment with bisphosphonates and their safety in postmenopausal osteoporosis. Ther. Clin. Risk Manag. 2010, 6, 325-343.

41. Russell, R.G.G.; Watts, N.B.; Ebetino, F.H.; Rogers, M. Mechanisms of action of bisphosphonates: Similarities and differences and their potential influence on clinical efficacy. Osteoporos. Int. 2008, 19, 733-759. [CrossRef]

42. Ebetino, F.H.; Hogan, A.-M.L.; Sun, S.; Tsoumpra, M.K.; Duan, X.; Triffitt, J.T.; Kwaasi, A.A.; Dunford, J.; Barnett, B.L.; Oppermann, U.; et al. The relationship between the chemistry and biological activity of the bisphosphonates. Bone 2011, 49, 20-33. [CrossRef] [PubMed]

43. Wang, H.; Xiao, L.; Tao, J.; Srinivasan, V.; Boyce, B.F.; Ebetino, F.H.; Oyajobi, B.O.; Boeckman, J.R.K.; Xing, L. Synthesis of a Bone-Targeted Bortezomib with In Vivo Anti-Myeloma Effects in Mice. Pharmaceutics 2018, 10, 154. [CrossRef] [PubMed]

44. Wang, H.; Zhang, H.; Srinivasan, V.; Tao, J.; Sun, W.; Lin, X.; Wu, T.; Boyce, B.F.; Ebetino, F.H.; Boeckman, R.K.; et al. Targeting Bortezomib to Bone Increases Its Bone Anabolic Activity and Reduces Systemic Adverse Effects in Mice. J. Bone Miner. Res. 2020, 35, 343-356. [CrossRef] [PubMed]

45. Farrell, K.B.; Karpeisky, A.; Thamm, D.H.; Zinnen, S. Bisphosphonate conjugation for bone specific drug targeting. Bone Rep. 2018, 9, 47-60. [CrossRef] [PubMed]

46. Xing, L.; Ebetino, F.H.; Boeckman, R.K.; Srinivasan, V.; Tao, J.; Sawyer, T.K.; Li, J.; Yao, Z.; Boyce, B.F. Targeting anti-cancer agents to bone using bisphosphonates. Bone 2020, 138, 115492. [CrossRef]

47. Rotman, S.; Grijpma, D.; Richards, R.; Moriarty, F.; Eglin, D.; Guillaume, O. Drug delivery systems functionalized with bone mineral seeking agents for bone targeted therapeutics. J. Control. Release 2018, 269, 88-99. [CrossRef]

48. Rotman, S.G.; Thompson, K.; Grijpma, D.W.; Richards, R.G.; Moriarty, T.F.; Eglin, D.; Guillaume, O. Development of bone seeker-functionalised microspheres as a targeted local antibiotic delivery system for bone infections. J. Orthop. Transl. 2020, 21, 136-145. [CrossRef]

49. Rotman, S.G.; Moriarty, T.F.; Nottelet, B.; Grijpma, D.W.; Eglin, D.; Guillaume, O. Poly(Aspartic Acid) Functionalized Poly(єCaprolactone) Microspheres with Enhanced Hydroxyapatite Affinity as Bone Targeting Antibiotic Carriers. Pharmaceutics 2020, 12, 885. [CrossRef]

50. Trombetta, R.P.; Dunman, P.M.; Schwarz, E.M.; Kates, S.L.; Awad, H.A. A High-Throughput Screening Approach to Repurpose FDA-Approved Drugs for Bactericidal Applications against Staphylococcus aureus Small-Colony Variants. mSphere 2018, 3, e00422-18. [CrossRef]

51. Trombetta, R.P.; Ninomiya, M.J.; El-Atawneh, I.M.; Knapp, E.K.; Bentley, K.L.D.M.; Dunman, P.M.; Schwarz, E.M.; Kates, S.L.; Awad, H.A. Calcium Phosphate Spacers for the Local Delivery of Sitafloxacin and Rifampin to Treat Orthopedic Infections: Efficacy and Proof of Concept in a Mouse Model of Single-Stage Revision of Device-Associated Osteomyelitis. Pharmaceutics 2019, 11, 94. [CrossRef] [PubMed]

52. Gidari, A.; Sabbatini, S.; Schiaroli, E.; Perito, S.; Francisci, D.; Baldelli, F.; Monari, C. Tedizolid-Rifampicin Combination Prevents Rifampicin-Resistance on in vitro Model of Staphylococcus aureus Mature Biofilm. Front. Microbiol. 2020, 11, 2085. [CrossRef] [PubMed] 